\title{
Uma Experiência de Classificação de Cargos
}

\author{
Manoel Alves Mendes Júnior
}

\begin{abstract}
A
pós exercer por um ano ininterrupto, em primeira ocupação, e dêle ser exonerado, o cargo de Chefe do Serviço de Classificação cie Cargos da Secretaria Geral de Administração do Estado da Guanabara, consideramos de bom alvitre oferecer aos colegas do serviço público civil um apanhado despretensioso da experiência vivida à frente daquele Serviço, sem qualquer propósito de pontificar sôbre técnicas de classificação de cargos.

O desejo de servir a um amigo comum, aliado ao vivo interêsse que, inegàvelmente, despertou em nós essa atividade de administração de pessoal, fêz que as dificuldades inerentes a empreendimentos dessa natureza não pesassem na balança de nossa decisão. Ao aceitar o convite do Dr. Luiz Carlos Mancini para exercer aquêle cargo - exercício êsse a que devemos valiosa experiência - sabiamos das condições em que se iria processar a implantação do sistema de classificação de cargos na administração do Estado da Guanabara. À nossa decisão, todavia, não era estranho o desejo de servir à terra natal que, após recuperar a autonomia, iniciava nova fase de sua vida política como o Estado benjamim da Federação.
\end{abstract}

Não ignorávamos que são tantos os problemas e as dificulcades que surgem durante a implantação de um plano de classificação à base de atribuições e responsabilidades que sòmente as administrações superiormente orientadas e aparelhadas poderão levar a bom têrmo tão espinhosa tarefa. A vasta bibliografia existente sôbre o assunto revela que mesmo nos Estados Unidos da América, cuja experiência neste particular é decisiva, a classificação de cargos suscita muita controvérsia, sobretudo nos meios sindicais e operários.

Se naquele país a classificação de cargos, após cinqüenta anos, ainda acarreta objeções importantes em certos meios, não obstante a experiência acumulada nesse periodo, fácil é avaliar o que poderá ocorrer entre nós - como de fato está ocorrendo - a ponto de certos especialistas aventarem que essa importante atividade da administração de pessoal está irremediàvelmente comprometida por atitudes a que não são estranhas a ignorância, a incompreensão, a hostilidade até.

Por parte do funcionalismo, total ausência de senso autocritico combinada com irrecusável luta por melhores vencimentos e salários em face da elevação dos niveis do custo-de-vida impe- 
dem, quer na fase de elaboração, quer na de implantação, que o interêsse coletivo, em última análise o próprio interêsse público, prevaleça sôbre o interêsse individual ou de grupos. A êsse comportamento já de si catastrófico vem juntar-se, para agravar mais o problema, a incompreensão da administração perante os aspectos atuais das relações entre o funcionário e o Estado.

Quer se trate da classificação de cargos na administração federal, quer na do Estado da Guanabara, os equívocos foram os mesmos. O funcionário não foi conduzido para um clima favorável à classificação de cargos porque a administração fracassou ao se omitir no que tem sido considerado de suma importância - uma politica de informação e cooperação inteligente e sincera que vinculasse o funcionário à classificação de cargos como o criador à sua criatura, à sua obra.

A necessidade de associar o funcionário à elaboração e implantação de um sistema de classificação de cargos justifica-se plenamente pela conveniência de dissipar temores, pois o funcionalismo em geral receia que a administração tem interêsse em obter vantagens em seu detrimento, com o auxílio de técnicos que cscapam à sua compreensão. Onde normalmente o funcionário tècnicamente qualificado percebe um esfôrço de racionalização, o funcionário operário julga ver uma modificação desfavorável de sua situação funcional.

Por outro lado, improvidência, improvisação e impaciência são freqüentemente os traços predominantes de nossas atividades. Disposições ou medidas prévias para conseguir determinado fim, remediar qualquer necessidade ou regularizar certos serviços não são providenciadas freqüentemente a tempo. Em conseqüência, surgem os arranjos improvisados, as soluções de momento que, à mingua de planejamento criterioso, geram o desencanto próprio dos resultados frustrados, das soluções inadequadas.

A elaboração da Lei $n^{\circ} 14$, de 24 de outubro de 1960, é sob certos aspectos um exemplo de improvisação. A base legal repousa na sua congênere federal, a Lei $n^{\circ} 3.780$, de 12 de julho de 1960. A estrutura técnica, pelo contrário, tem sua originalidade. $O$ toque original, entretanto, não impede que se diga: a elaboração do plano de classificação de cargos da administração estadual foi fortemente influenciada pela promulgação daquela lei federal e, também, o que nos parece mais próximo da verdade, pelo empenho de apresentar mais uma realização expressiva no balanço do govêrno Sette Câmara.

Do afogadilho de sua discussão e votação na Câmara Legislativa serve de exemplo a colaboração do Poder Executivo do Estado: até hoje, é difícil afirmar em sã consciência se o plano elaborado pela Secretaria de Administração em tempo recorde pode ser considerado um substitutivo à Mensagem $n^{\circ} 5$, anteriurmente enviada à Câmara dos Vereadores ou um projeto nôvo, 
desvinculado do anterior. Outrossim, se aceito como substitutivo, ainda mais dificil se torna conhecer-lhe a paternidade, pois uns consideram-no uma iniciativa do Poder Executivo, outros uma colaboração dada por êste ao Poder Legislativo. De qualquer modo, a carência de recursos orçamentários em 1960 era de tal ordem que a Lei $n^{\circ} 14$, promulgada a 24 de outubro, permaneceu inoperante, na parte de classificação de cargos, pelo resto do ano.

Se não tôdas, pelo menos grande parte das premissas que se consideram usualmente necessárias para o bom êxito de um sistema de classificação de cargos estiveram ausentes no Estado da Guanabara. A Lei n' 14 criou o sistema de órgãos para a administração do plano, mas dessa providência, é óbvio, não se poderiam esperar milagres. Muita coisa poderia ser dita com referência à própria Lei $n^{\circ} 14 / 60$. A exposição, entretanto, alongar-se-ia demasiado em prejuizo do que objetivamos relatar, que é a nossa própria experiência iniciada em 2 de janeiro de 1961 .

O sistema de órgãos criados ou previstos na Lei $n^{\circ} 14 / 60$ para implantação e administração do plano é integrado pela Comissão de Classificação de Cargos, diretamente subordinada ao Secretário de Estado de Administração, pelo Serviço de Classiticação de Cargos com a mesma subordinação e pelos Setores de Classificação de Cargos integrados inicialmente nos Serviços de Administração das Secretarias Gerais e mais tarde subordinados aos titulares destas. A êsse sistema, sem nenhuma tradição ' u experiência prévia em atividades de classificação de cargos, caberia a responsabilidade de impulsionar o estudo, planejamento, execução, registro e contrôle do enquadramento do pesosal estadual.

Quanto ao Serviço de Classificação de Cargos, era êste o panorama após dois meses de vigência da Lei $n^{\circ} 14 / 60$, quando tomamos posse: o serviço não possuia local para se instalar e funcionar; não the havia sido consignada na lei de meios qualquer dotação orçamentária; não havia, outrossim, qualquer crédito especial, aprovado ou em tramitação na Assembléia Legislativa, provendo-o de recursos; não tendo local para funcionar, também, não possuía móveis e equipamentos; não tinha lotação de pessoal; não dispunha do mais modesto estoque de material de consumo; não dispunha de qualquer documentação administrativa, quer no tocante a cadastro de pessoal, quer a respeito de levantamentos da situação existente.

Assim, paralelamente às suas tarefas especificas - que se iniciaram com a elaboração do regimento do S.C.C., realização de um ciclo de reuniões com palestras sôbre a execução da Lei $n^{\circ} 14 / 60$ e participação das reuniões da Comissão - teve o Chefe que se colocar na posição do administrador de orçamento, pessoal e material para preocupar-se com a obtenção de salas de trabalho, recrutamento de pessoal, aquisição de material permanente e de consumo, instalação de telefone, etc. As soluções eram 
sempre precárias. No período de um ano, por exemplo, o Serviço funcionou em três locais diferentes. Quando, afinal, começaram a ser entregues as primeiras máquinas de escrever novas, já estávamos em novembro. Móveis adequados, ao que estamos infor mados, só foram fornecidos já em 1962.

A improvidência, como dissemos acima, levou à improvisação. Não tínhamos móveis apropriados; aceitamos móveis já considerados imprestáveis que a boa vontade dos artifices conseguia recuperar a duras penas. As máquinas de escrever obsoletas, uma cedida pelo Serviço de Planejamento e as demais pelo Serviço de Administração da Secretaria Geral de Educação, nem para a rotina interna serviam.

Para um cadastro minimo e indispensável do pessoal a enquadrar, recorremos às doações de cartolina que, de forma precaríssima, permitiram a confecção de pequenas fichas em que se registravam os dados minimos sôbre a situação funcional e sôbre as condições básicas e específicas apresentadas pelos candidatos a enquadramento. Tais fichas, que ultrapassaram oitenta mil unidades, eram colecionadas em tabuleiros de madeira confeccionados nas oficinas da Secretaria Geral de Administração.

Não alcançou duas dezenas o número de funcionários lotados no Serviço no primeiro ano de seu funcionamento. Dêsses, apenas doze apresentavam exercicio regular: três Chefes de Setor, um Oficial Administrativo, um Auxiliar Administrativo, um Escriturário, um Auxiliar de Escritório, um Auxiliar de Registrador, um Datilógrafo Auxiliar, um Enfermeiro, um Estafeta e um Trabalhador. Dêsses doze, apenas seis tinham treinamento funcional bastante para estudar e opinar sôbre as propostas de enquadramento.

Diante dêsse quadro, as perspectivas para o enquadramento eram inegàvelmente sombrias. Em 3 de agôsto, comunicamos ao Sr. Secretário de Administração, pelo Ofício n 38 do S.C.C., quais seriam as nossas possibilidades de enquadramento de pessoal e confessávamos que nos contentariamos com a lotação de quatro datilógrafos acompanhados das respectivas máquinas de escrever para lograrmos enquadrar 40.000 (quarenta mil) funcionários. Desnecessário seria acrescentar que não fomos atendidos.

Desprovido de meios materiais, sem equipamento, sem pessoal qualificado em númearo razoável para o desempenho das suas atribuições, não alcançou o Serviço de Classificação de Cargos o tão desejado aparelhamento que lhe asseguraria permanentes iniciativa e eficiência, necessárias ao regular enquadramento do pessoal do Estado. Não fôra o elevado espírito público de um punhado de servidores do Serviço e de outras Secretarias Gerais e das autarquias estaduais, que não poupou esforços, em regime de tempo integral, para nos ajudar a vencer, ao menos em parte, as dificuldades existentes, o Serviço teria fracassado no exercício da sua competência. 
Os que estão familiarizados com as características da Lei número $14 / 60$ que, no tocante ao enquadramento, não seguiu a orientação da lei federal, antes preferiu instituir um sistema de verificação das qualificações individuais dos funcionários, podem avaliar o que foi o exame de propostas de enquadramento, acompanhadas de copiosa documentação, de mais de 17.500 (dezessete mil e quinhentos) funcionários, por equipe tão reduzida.

Recapitulando: com tal carência de recursos em pessoal e material, que o Dr. Luiz Carlos Mancini tantas vêzes qualificou de pobreza franciscana, o Serviço de Classificação de Cargos conseguitu:

1ค) elaborar o seu próprio regimento;

2:) realizar um ciclo de reuniões de treinamento com o pessoal inicialmente escolhido para os Setores de Classificação de Cargos;

3) elaborar e submeter à Comissão de Classificação de Cargos substitutivos aos planos de classificação de cargos do Departamento de Estradas de Rodagem e do Montepio dos Empregados Municipais e examinar o da Administração dos Estádios Municipais;

4.) examinar propostas de enquadramento de aproximadamente 17.500 (dezessete mil e quinhentos) servidores do Estado;

5:) enquadrar, entre 9 de junho de 1961, data em que o Serviço recebeu a primeira proposta, e 31 de dezembro do mesmo ano, mais de 16.600 (dezesseis mil e seiscentos) servidores, dos quais 15.148 (quinze mil, cento e quarenta e oito) já incluídos em decretos submetidos à assinatura do Governador;

6\%) atender a numerosas solicitações como sejam, entre outras, opinar em processos, elaborar projetos de lei e de decreto, projetar formulários e fichas, elaborar listas de conversão para enquadramento, dar assistência técnica aos Setores de Classificação de Cargos.

Ao findar o ano de nossa gestão à frente do Serviço, sem têrmos concluido o enquadramento, encerrávamos nossas atividades convencidos de que o sistema de classificação de cargos instituido pela Lei $n^{\text {? }} 14 / 60$, hostilizado pelo funcionalismo e abandonado pela administração, era mais uma reestruturação de cargos e carreiras, a acrescentar às já realizadas, com a qual o serviço civil do Estado da Guanabara nada tinha a ganhar. Para confirmar o nosso ponto-de-vista basta acrescentar que em dezembro, pouco mais de um ano após a vigência da Lei $\mathrm{n}^{\circ} 14 / 60$, era promulgada a Lei $n^{\circ} 134$, que reestruturou pràticamente todo o sistema vigente.

Dessa experiência saímos convencidos de que a técnica de classificação de cargos como um dos instrumentos mais valiosos 
da organização cientifica do trabalho não conseguiu ainda captar a adesão consciente nem dos responsáveis pela coisa pública nem do funcionalismo em geral. Os primeiros ainda não se convenceram de que é fundamental na luta contra o subdesenvolvimento organizar a administração pública em bases racionais, armando-a de uma politica de pessoal que obtenha a aceitação dos diversos grupos profissionais por ela afetados. Os funcionários, por sua vez, não são chamados a participar diretamente na elaboração dessa politica, que mesmo medianamente aceitável sob o aspecto técnico poderá funcionar bem desde que nela se acredite.

Hoje, acreditamos que, com essa orientação, é possível derrotar a improvidência, a improvisação e a impaciência, essa trilogia que tantos prejuizos causa ao serviço civil em geral. 